\section{Design-Based Research: A Methodology to Extend and Enrich Biology Education Research}

\author{
Emily E. Scott,* Mary Pat Wenderoth, and Jennifer H. Doherty
}

Department of Biology, University of Washington, Seattle, WA 98195

\begin{abstract}
Recent calls in biology education research (BER) have recommended that researchers leverage learning theories and methodologies from other disciplines to investigate the mechanisms by which students to develop sophisticated ideas. We suggest design-based research from the learning sciences is a compelling methodology for achieving this aim. Design-based research investigates the "learning ecologies" that move student thinking toward mastery. These "learning ecologies" are grounded in theories of learning, produce measurable changes in student learning, generate design principles that guide the development of instructional tools, and are enacted using extended, iterative teaching experiments. In this essay, we introduce readers to the key elements of design-based research, using our own research into student learning in undergraduate physiology as an example of design-based research in BER. Then, we discuss how design-based research can extend work already done in BER and foster interdisciplinary collaborations among cognitive and learning scientists, biology education researchers, and instructors. We also explore some of the challenges associated with this methodological approach.
\end{abstract}

\section{INTRODUCTION}

There have been recent calls for biology education researchers to look toward other fields of educational inquiry for theories and methodologies to advance, and expand, our understanding of what helps students learn to think like biologists (Coley and Tanner, 2012; Dolan, 2015; Peffer and Renken, 2016; Lo et al., 2019). These calls include the recommendations that biology education researchers ground their work in learning theories from the cognitive and learning sciences (Coley and Tanner, 2012) and begin investigating the underlying mechanisms by which students to develop sophisticated biology ideas (Dolan, 2015; Lo et al., 2019). Design-based research from the learning sciences is one methodology that seeks to do both by using theories of learning to investigate how "learning ecologies"- that is, complex systems of interactions among instructors, students, and environmental components-support the process of student learning (Brown, 1992; Cobb et al., 2003; Collins et al., 2004; Peffer and Renken, 2016).

The purpose of this essay is twofold. First, we want to introduce readers to the key elements of design-based research, using our research into student learning in undergraduate physiology as an example of design-based research in biology education research (BER). Second, we will discuss how design-based research can extend work already done in BER and explore some of the challenges of its implementation. For a more in-depth review of design-based research, we direct readers to the following references: Brown (1992), Barab and Squire (2004), and Collins et al. (2004), as well as commentaries by Anderson and Shattuck (2012) and McKenney and Reeves (2013).

\section{WHAT IS DESIGN-BASED RESEARCH?}

Design-based research is a methodological approach that aligns with research methods from the fields of engineering or applied physics, where products are designed for
Kimberly Tanner, Monitoring Editor Submitted Nov 18, 2019; Revised Mar 3, 2020; Accepted Mar 25, 2020

CBE Life Sci Educ June 1, 2020 19:es11

DOI:10.1187/cbe.19-11-0245

*Address correspondence to: Emily E. Scott (scottemi@uw.edu).

(C) 2020 E. E. Scott et al. CBE-Life Sciences Education ๑ 2020 The American Society for Cell Biology. This article is distributed by The American Society for Cell Biology under license from the author(s). It is available to the public under an Attribution-Noncommercial-Share Alike 3.0 Unported Creative Commons License (http://creativecommons.org/licenses/ by-nc-sa/3.0).

"ASCB $® "$ and "The American Society for Cell Biology ${ }^{\circledR}$ " are registered trademarks of The American Society for Cell Biology. 

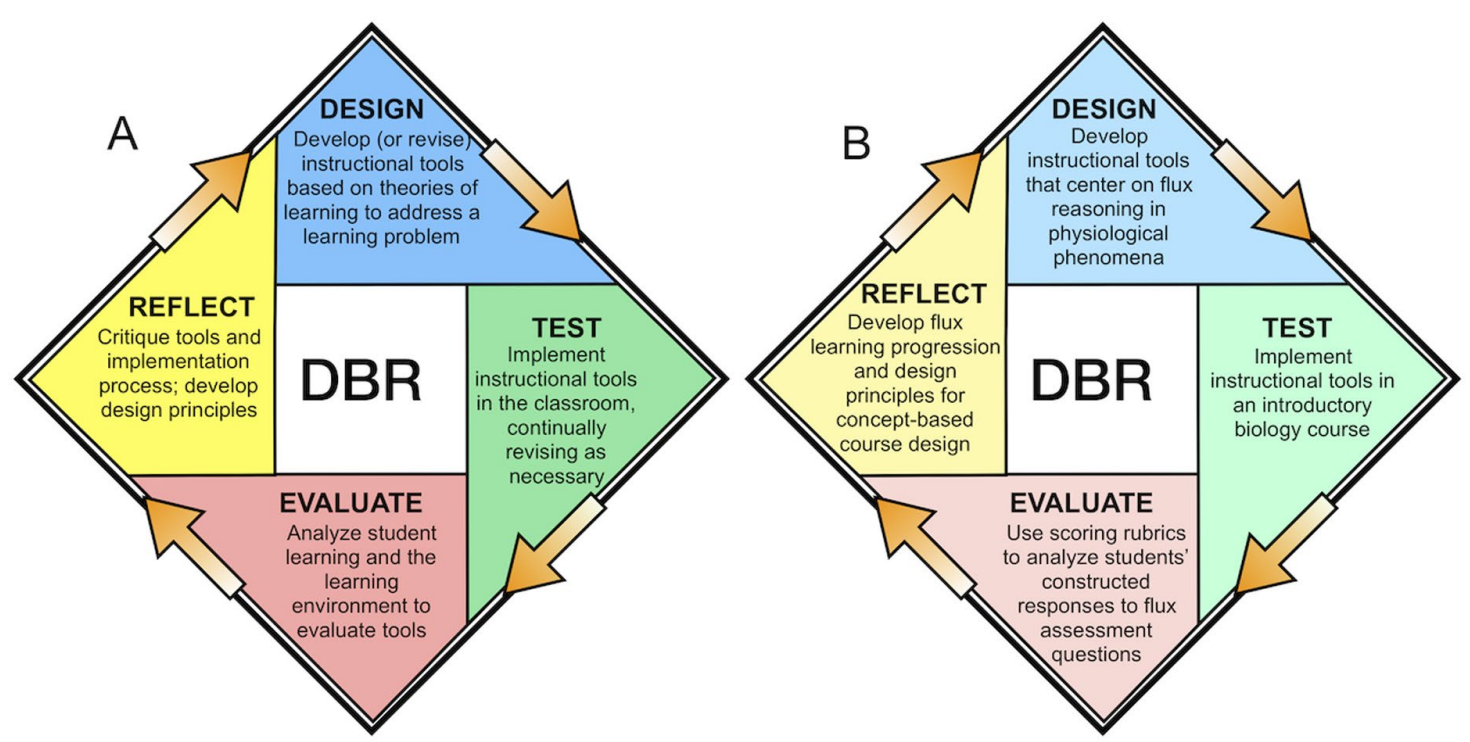

FIGURE 1. The four phases of design-based research experienced in an iterative cycle (A). We also highlight the main features of each phase of our design-based research project investigating students' use of flux in physiology (B).

specific purposes (Brown, 1992; Joseph, 2004; Middleton et al., 2008; Kelly, 2014). Consequently, investigators using designbased research approach educational inquiry much as an engineer develops a new product: First, the researchers identify a problem that needs to be addressed (e.g., a particular learning challenge that students face). Next, they design a potential "solution" to the problem in the form of instructional tools (e.g., reasoning strategies, worksheets; e.g., Reiser et al., 2001) that theory and previous research suggest will address the problem. Then, the researchers test the instructional tools in a real-world setting (i.e., the classroom) to see if the tools positively impact student learning. As testing proceeds, researchers evaluate the instructional tools with emerging evidence of their effectiveness (or lack thereof) and progressively revise the tools-in real time-as necessary (Collins et al., 2004). Finally, the researchers reflect on the outcomes of the experiment, identifying the features of the instructional tools that were successful at addressing the initial learning problem, revising those aspects that were not helpful to learning, and determining how the research informed the theory underlying the experiment. This leads to another research cycle of designing, testing, evaluating, and reflecting to refine the instructional tools in support of student learning. We have characterized this iterative process in Figure 1 after Sandoval (2014). Though we have portrayed four discrete phases to design-based research, there is often overlap of the phases as the research progresses (e.g., testing and evaluating can occur simultaneously).

Design-based research has no specific requirements for the form that instructional tools must take or the manner in which the tools are evaluated (Bell, 2004; Anderson and Shattuck, 2012). Instead, design-based research has what Sandoval (2014) calls "epistemic commitments" ${ }^{1}$ that inform the major goals of a design-based research project as well as how it is implemented. These epistemic commitments are: 1) Design

\footnotetext{
1"Epistemic commitment" is defined as engaging in certain practices that generate knowledge in an agreed-upon way.
}

based research should be grounded in theories of learning (e.g., constructivism, knowledge-in-pieces, conceptual change) that both inform the design of the instructional tools and are improved upon by the research (Cobb et al., 2003; Barab and Squire, 2004). This makes design-based research more than a method for testing whether or not an instructional tool works; it also investigates why the design worked and how it can be generalized to other learning environments (Cobb et al., 2003). 2) Design-based research should aim to produce measurable changes in student learning in classrooms around a particular learning problem (Anderson and Shattuck, 2012; McKenney and Reeves, 2013). This requirement ensures that theoretical research into student learning is directly applicable, and impactful, to students and instructors in classroom settings (Hoadley, 2004). 3) Design-based research should generate design principles that guide the development and implementation of future instructional tools (Edelson, 2002). This commitment makes the research findings broadly applicable for use in a variety of classroom environments. 4) Design-based research should be enacted using extended, iterative teaching experiments in classrooms. By observing student learning over an extended period of time (e.g., throughout an entire term or across terms), researchers are more likely to observe the full effects of how the instructional tools impact student learning compared with short-term experiments (Brown, 1992; Barab and Squire, 2004; Sandoval and Bell, 2004).

\section{HOW IS DESIGN-BASED RESEARCH DIFFERENT FROM AN EXPERIMENTAL APPROACH?}

Many BER studies employ experimental approaches that align with traditional scientific methods of experimentation, such as using treatment versus control groups, randomly assigning treatments to different groups, replicating interventions across multiple spatial or temporal periods, and using statistical methods to guide the kinds of inferences that arise from an experiment. While design-based research can similarly employ these strategies for educational inquiry, there are also some 
notable differences in its approach to experimentation (Collins et al., 2004; Hoadley, 2004). In this section, we contrast the differences between design-based research and what we call "experimental approaches," although both paradigms represent a form of experimentation.

The first difference between an experimental approach and design-based research regards the role participants play in the experiment. In an experimental approach, the researcher is responsible for making all the decisions about how the experiment will be implemented and analyzed, while the instructor facilitates the experimental treatments. In design-based research, both researchers and instructors are engaged in all stages of the research from conception to reflection (Collins et al., 2004). In BER, a third condition frequently arises wherein the researcher is also the instructor. In this case, if the research questions being investigated produce generalizable results that have the potential to impact teaching broadly, then this is consistent with a design-based research approach (Cobb et al., 2003). However, when the research questions are self-reflective about how a researcher/instructor can improve his or her own classroom practices, this aligns more closely with "action research," which is another methodology used in education research (see Stringer, 2013).

A second difference between experimental research and design-based research is the form that hypotheses take and the manner in which they are investigated (Collins et al., 2004; Sandoval, 2014). In experimental approaches, researchers develop a hypothesis about how a specific instructional intervention will impact student learning. The intervention is then tested in the classroom(s) while controlling for other variables that are not part of the study in order to isolate the effects of the intervention. Sometimes, researchers designate a "control" situation that serves as a comparison group that does not experience the intervention. For example, Jackson et al. (2018) were interested in comparing peer- and self-grading of weekly practice exams to if they were equally effective forms of deliberate practice for students in a large-enrollment class. To test this, the authors (including authors of this essay J.H.D., M.P.W.) designed an experiment in which lab sections of students in a large lecture course were randomly assigned to either a peer-grading or self-grading treatment so they could isolate the effects of each intervention. In design-based research, a hypothesis is conceptualized as the "design solution" rather than a specific intervention; that is, design-based researchers hypothesize that the designed instructional tools, when implemented in the classroom, will create a learning ecology that improves student learning around the identified learning problem (Edelson, 2002; Bell, 2004). For example, Zagallo et al. (2016) developed a laboratory curriculum (i.e., the hypothesized "design solution") for molecular and cellular biology majors to address the learning problem that students often struggle to connect scientific models and empirical data. This curriculum entailed: focusing instruction around a set of target biological models; developing small-group activities in which students interacted with the models by analyzing data from scientific papers; using formative assessment tools for student feedback; and providing students with a set of learning objectives they could use as study tools. They tested their curriculum in a novel, large-enrollment course of upper-division students over several years, making iterative changes to the curriculum as the study progressed.
By framing the research approach as an iterative endeavor of progressive refinement rather than a test of a particular intervention when all other variables are controlled, design-based researchers recognize that: 1) classrooms, and classroom experiences, are unique at any given time, making it difficult to truly "control" the environment in which an intervention occurs or establish a "control group" that differs only in the features of an intervention; and 2) many aspects of a classroom experience may influence the effectiveness of an intervention, often in unanticipated ways, which should be included in the research team's analysis of an intervention's success. Consequently, the research team is less concerned with controlling the research conditions - as in an experimental approach-and instead focuses on characterizing the learning environment (Barab and Squire, 2004). This involves collecting data from multiple sources as the research progresses, including how the instructional tools were implemented, aspects of the implementation process that failed to go as planned, and how the instructional tools or implementation process was modified. These characterizations can provide important insights into what specific features of the instructional tools, or the learning environment, were most impactful to learning (DBR Collective, 2003).

A third difference between experimental approaches and design-based research is when the instructional interventions can be modified. In experimental research, the intervention is fixed throughout the experimental period, with any revisions occurring only after the experiment has concluded. This is critical for ensuring that the results of the study provide evidence of the efficacy of a specific intervention. By contrast, designbased research takes a more flexible approach that allows instructional tools to be modified in situ as they are being implemented (Hoadley, 2004; Barab, 2014). This flexibility allows the research team to modify instructional tools or strategies that prove inadequate for collecting the evidence necessary to evaluate the underlying theory and ensures a tight connection between interventions and a specific learning problem (Collins et al., 2004; Hoadley, 2004).

Finally, and importantly, experimental approaches and design-based research differ in the kinds of conclusions they draw from their data. Experimental research can "identify that something meaningful happened; but [it is] not able to articulate what about the intervention caused that story to unfold" (Barab, 2014, p. 162). In other words, experimental methods are robust for identifying where differences in learning occur, such as between groups of students experiencing peer- or self-grading of practice exams (Jackson et al., 2018) or receiving different curricula (e.g., Chi et al., 2012). However, these methods are not able to characterize the underlying learning process or mechanism involved in the different learning outcomes. By contrast, design-based research has the potential to uncover mechanisms of learning, because it investigates how the nature of student thinking changes as students experience instructional interventions (Shavelson et al., 2003; Barab, 2014). According to Sandoval (2014), "Design research, as a means of uncovering causal processes, is oriented not to finding effects but to finding functions, to understanding how desired (and undesired) effects arise through interactions in a designed environment" (p. 30). In Zagallo et al. (2016), the authors found that their curriculum supported students' data-interpretation skills, because it stimulated students' spontaneous use of 
argumentation during which group members coconstructed evidence-based claims from the data provided. Students also worked collaboratively to decode figures and identify data patterns. These strategies were identified from the researchers' qualitative data analysis of in-class recordings of small-group discussions, which allowed them to observe what students were doing to support their learning. Because design-based research is focused on characterizing how learning occurs in classrooms, it can begin to answer the kinds of mechanistic questions others have identified as central to advancing BER (National Research Council [NRC], 2012; Dolan, 2015; Lo et al., 2019).

\section{DESIGN-BASED RESEARCH IN ACTION: AN EXAMPLE FROM UNDERGRADUATE PHYSIOLOGY}

To illustrate how design-based research could be employed in BER, we draw on our own research that investigates how students learn physiology. We will characterize one iteration of our design-based research cycle (Figure 1), emphasizing how our project uses Sandoval's four epistemic commitments (i.e., theory driven, practically applied, generating design principles, implemented in an iterative manner) to guide our implementation.

\section{Identifying the Learning Problem}

Understanding physiological phenomena is challenging for students, given the wide variety of contexts (e.g., cardiovascular, neuromuscular, respiratory; animal vs. plant) and scales involved (e.g., using molecular-level interactions to explain organism functioning; Wang, 2004; Michael, 2007; Badenhorst et al., 2016). To address these learning challenges, Modell (2000) identified seven "general models" that undergird most physiology phenomena (i.e., control systems, conservation of mass, mass and heat flow, elastic properties of tissues, transport across membranes, cell-to-cell communication, molecular interactions). Instructors can use these models as a "conceptual framework" to help students build intellectual coherence across phenomena and develop a deeper understanding of physiology (Modell, 2000; Michael et al., 2009). This approach aligns with theoretical work in the learning sciences that indicates that providing students with conceptual frameworks improves their ability to integrate and retrieve knowledge (National Academies of Sciences, Engineering, and Medicine, 2018).

Before the start of our design-based project, we had been using Modell's (2000) general models to guide our instruction. In this essay, we will focus on how we used the general models of mass and heat flow and transport across membranes in our instruction. These two models together describe how materials flow down gradients (e.g., pressure gradients, electrochemical gradients) against sources of resistance (e.g., tube diameter, channel frequency). We call this flux reasoning. We emphasized the fundamental nature and broad utility of flux reasoning in lecture and lab and frequently highlighted when it could be applied to explain a phenomenon. We also developed a conceptual scaffold (the Flux Reasoning Tool) that students could use to reason about physiological processes involving flux.

Although these instructional approaches had improved students' understanding of flux phenomena, we found that students often demonstrated little commitment to using flux broadly across physiological contexts. Instead, they considered flux to be just another fact to memorize and applied it to nar- row circumstances (e.g., they would use flux to reason about ions flowing across membranes-the context where flux was first introduced-but not the bulk flow of blood in a vessel). Students also struggled to integrate the various components of flux (e.g., balancing chemical and electrical gradients, accounting for variable resistance). We saw these issues reflected in students' lower than hoped for exam scores on the cumulative final of the course. From these experiences, and from conversations with other physiology instructors, we identified a learning problem to address through design-based research: How do students learn to use flux reasoning to explain material flows in multiple physiology contexts?

The process of identifying a learning problem usually emerges from a researcher's own experiences (in or outside a classroom) or from previous research that has been described in the literature (Cobb et al., 2003). To remain true to Sandoval's first epistemic commitment, a learning problem must advance a theory of learning (Edelson, 2002; McKenney and Reeves, 2013). In our work, we investigated how conceptual frameworks based on fundamental scientific concepts (i.e., Modell's general models) could help students reason productively about physiology phenomena (National Academies of Sciences, Engineering, and Medicine, 2018; Modell, 2000). Our specific theoretical question was: Can we characterize how students' conceptual frameworks around flux change as they work toward robust ideas? Sandoval's second epistemic commitment stated that a learning problem must aim to improve student learning outcomes. The practical significance of our learning problem was: Does using the concept of flux as a foundational idea for instructional tools increase students' learning of physiological phenomena?

We investigated our learning problem in an introductory biology course at a large R1 institution. The introductory course is the third in a biology sequence that focuses on plant and animal physiology. The course typically serves between 250 and 600 students in their sophomore or junior years each term. Classes have the following average demographics: $68 \%$ male, $21 \%$ from lower-income situations, $12 \%$ from an underrepresented minority, and $26 \%$ first-generation college students.

\section{Design-Based Research Cycle 1, Phase 1: Designing Instructional Tools}

The first phase of design-based research involves developing instructional tools that address both the theoretical and practical concerns of the learning problem (Edelson, 2002; Wang and Hannafin, 2005). These instructional tools can take many forms, such as specific instructional strategies, classroom worksheets and practices, or technological software, as long as they embody the underlying learning theory being investigated. They must also produce classroom experiences or materials that can be evaluated to determine whether learning outcomes were met (Sandoval, 2014). Indeed, this alignment between theory, the nature of the instructional tools, and the ways students are assessed is central to ensuring rigorous design-based research (Hoadley, 2004; Sandoval, 2014). Taken together, the instructional tools instantiate a hypothesized learning environment that will advance both the theoretical and practical questions driving the research (Barab, 2014).

In our work, the theoretical claim that instruction based on fundamental scientific concepts would support students' flux 
Flux/Flow Thought Organizer

When a question or problem is about the direction or rate of movement of something, do the following:

1. Identify what the something is. Draw a diagram of the situation (e.g., cell and surroundings with all relevant values).

2. Determine the direction(s) of the driving force(s) acting on the something. Add a labeled arrow for each driving force.

3. If there is more than one driving force acting on the something determining the relative sizes of the driving forces. Indicate which arrow is the stronger force by making one thicker and one thinner.

4. Determine the resistances to movement of the something in this instance (inverse of the conductance). Make a note about sources of resistance.

5. Then, use this information to help answer the specific question.

(Note: if the problem states something is moving in contradiction flux, then active transport (primary or secondary) is involved.)

FIGURE 2. The Flux Reasoning Tool given to students at the beginning of the quarter.

considerably from the design team's initial expectations (Hoadley, 2004). During this phase, if necessary, the design team may make adjustments to the tools as they are being used to account for these unanticipated conditions (Collins et al., 2004).

We implemented the instructional tools during the Autumn and Spring quarters of the 2016-2017 academic year. Students were taught to use the Flux Reasoning Tool at the beginning of the term in the context of the first case study unit focused on neurophysiology. Each physiology unit throughout the term was associated with a new concept-based case study (usually about flux) that framed the context of the teaching. Embedded within the daily lectures were classroom activities in which students could practice using flux. Students were

reasoning was embodied in our instructional approach by being the central focus of all instructional materials, which included: a revised version of the Flux Reasoning Tool (Figure $2)$; case study-based units in lecture that explicitly emphasized flux phenomena in real-world contexts (Windschitl et al., 2012; Scott et al., 2018; Figure 3); classroom activities in which students practiced using flux to address physiological scenarios; links to online videos describing key flux-related concepts; constructed-response assessment items that cued students to use flux reasoning in their thinking; and pretest/ posttest formative assessment questions that tracked student learning (Figure 4).

\section{Phase 2: Testing the Instructional Tools}

In the second phase of design-based research, the instructional tools are tested by implementing them in classrooms. During this phase, the instructional tools are placed "in harm's way ... in order to expose the details of the process to scrutiny" (Cobb et al., 2003, p. 10). In this way, researchers and instructors test how the tools perform in real-world settings, which may differ also assigned readings from the textbook and videos related to flux to watch during each unit. Throughout the term, students took five exams that each contained some flux questions as well as some pre- and post-unit formative assessment questions. During Winter quarter, we conducted clinical interviews with students who would take our course in the Spring term (i.e., "pre" data) as well as students who had just completed our course in Autumn (i.e., "post" data).

\section{Phase 3: Evaluating the Instructional Tools}

The third phase of a design-based research cycle involves evaluating the effectiveness of instructional tools using evidence of student learning (Barab and Squire, 2004; Anderson and Shattuck, 2012). This can be done using products produced by students (e.g., homework, lab reports), attitudinal gains measured with surveys, participation rates in activities, interview testimonials, classroom discourse practices, and formative assessment or exam data (e.g., Reiser et al., 2001; Cobb et al., 2003; Barab and Squire, 2004; Mohan et al., 2009). Regardless of the source, evidence must be in a form that supports a systematic analysis
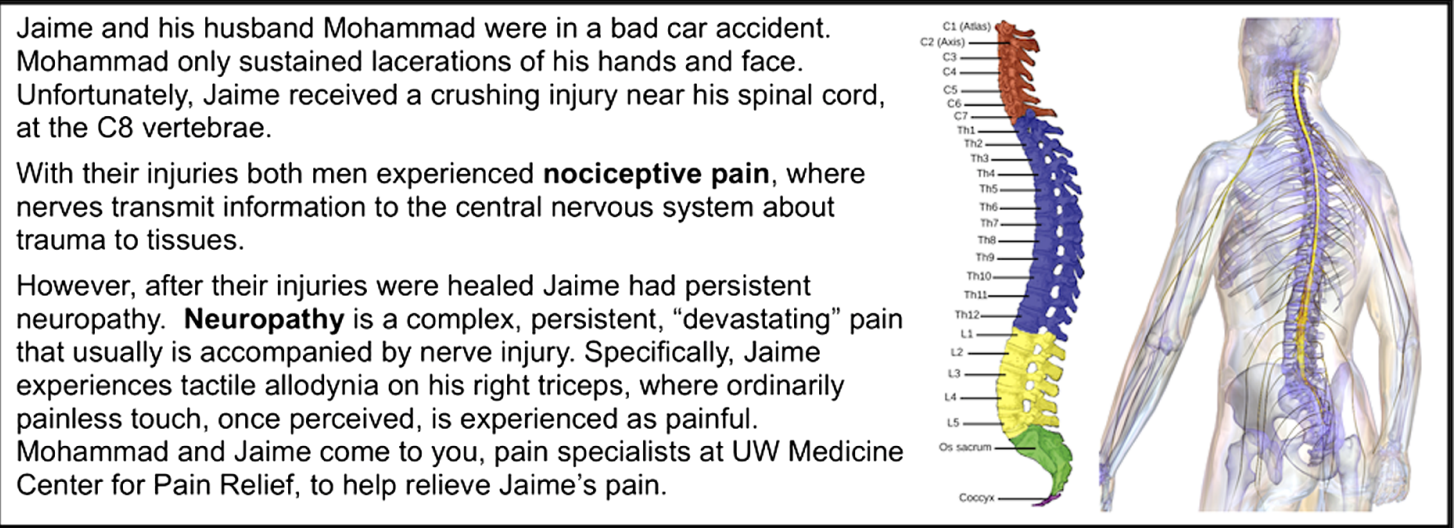

FIGURE 3. An example flux case study that is presented to students at the beginning of the neurophysiology unit. Throughout the unit, students learn how ion flows into and out of cells, as mediated by chemical and electrical gradients and various ion/molecular channels, sends signals throughout the body. They use this information to better understand why Jaime experiences persistent neuropathy. Images from: uz.wikipedia.org/wiki/Fayl:Blausen_0822_SpinalCord.png and commons.wikimedia.org/wiki/File:Figure_38_01_07.jpg. 


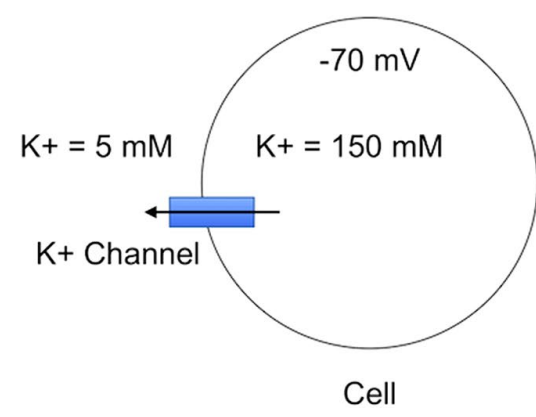

a) In the figure, there is net movement of $\mathrm{K}+$ ions out of the cell (as indicated by arrow). What can we change to cause net movement of $\mathrm{K}+$ INTO the cell? Identify as many ways as you can.

b) The reasons for my answers are:

FIGURE 4. An example flux assessment question about ion flows given in a pre-unit/ post-unit formative assessment in the neurophysiology unit.

that could be scrutinized by other researchers (Cobb et al., 2003; Barab, 2014). Also, because design-based research often involves multiple data streams, researchers may need to use both quantitative and qualitative analytical methods to produce a rich picture of how the instructional tools affected student learning (Collins et al., 2004; Anderson and Shattuck, 2012).

In our work, we used the quality of students' written responses on exams and formative assessment questions to determine whether students improved their understanding of physiological phenomena involving flux. For each assessment question, we analyzed a subset of student's pretest answers to identify overarching patterns in students' reasoning about flux, characterized these overarching patterns, then ordinated the patterns into different levels of sophistication. These became our scoring rubrics, which identified five different levels of student reasoning about flux. We used the rubrics to code the remainder of students' responses, with a code designating the level of student reasoning associated with a particular reasoning pattern. We used this ordinal rubric format because it would later inform our theoretical understanding of how students build flux conceptual frameworks (see phase 4). This also allowed us to both characterize the ideas students held about flux phenomena and identify the frequency distribution of those ideas in a class.

By analyzing changes in the frequency distributions of students' ideas across the rubric levels at different time points in the term (e.g., pre-unit vs. post-unit), we could track both the number of students who gained more sophisticated ideas about flux as the term progressed and the quality of those ideas. If the frequency of students reasoning at higher levels increased from pre-unit to post-unit assessments, we could conclude that our instructional tools as a whole were supporting students' development of sophisticated flux ideas. For example, on one neuromuscular ion flux assessment question in the Spring of 2017, we found that relatively more students were reasoning at the highest levels of our rubric (i.e., levels 4 and 5) on the post-unit test compared with the pre-unit test. This meant that more students were beginning to integrate sophisticated ideas about flux (i.e., they were balancing concentration and electrical gradients) in their reasoning about ion movement.

To help validate this finding, we drew on three additional data streams: 1) from in-class group recordings of students working with flux items, we noted that students increasingly incorporated ideas about gradients and resistance when constructing their explanations as the term progressed; 2) from plant assessment items in the latter part of the term, we began to see students using flux ideas unprompted; and 3) from interviews, we observed that students who had already taken the course used flux ideas in their reasoning.

Through these analyses, we also noticed an interesting pattern in the pre-unit test data for Spring 2017 when compared with the frequency distribution of students' responses with a previous term (Autumn 2016). In Spring 2017, $42 \%$ of students reasoned at level 4 or 5 on the pre-unit test, indicating these students already had sophisticated ideas about ion flux before they took the pre-unit assessment. This was surprising, considering only $2 \%$ of students reasoned at these levels for this item on the Autumn 2016 pre-unit test.

\section{Phase 4: Reflecting on the Instructional Tools and Their Implementation}

The final phase of a design-based research cycle involves a retrospective analysis that addresses the epistemic commitments of this methodology: How was the theory underpinning the research advanced by the research endeavor (theoretical outcome)? Did the instructional tools support student learning about the learning problem (practical outcome)? What were the critical features of the design solution that supported student learning (design principles)? (Cobb et al., 2003; Barab and Squire, 2004).

Theoretical Outcome (Epistemic Commitment 1). Reflecting on how a design-based research experiment advances theory is critical to our understanding of how students learn in educational settings (Barab and Squire, 2004; Mohan et al., 2009). In our work, we aimed to characterize how students' conceptual frameworks around flux change as they work toward robust ideas. To do this, we drew on learning progression research as our theoretical framing (NRC, 2007; Corcoran et al., 2009; Duschl et al., 2011; Scott et al., 2019). Learning progression frameworks describe empirically derived patterns in student thinking that are ordered into levels representing cognitive shifts in the ways students conceive a topic as they work toward mastery (Gunckel et al., 2012). We used our ion flux scoring rubrics to create a preliminary five-level learning progression framework (Table 1). The framework describes how students' ideas about flux often start with teleological-driven accounts at the lowest level (i.e., level 1), shift to focusing on driving forces (e.g., concentration gradients, electrical gradients) in the middle levels, and arrive at complex ideas that integrate multiple interacting forces at the higher levels. We further validated these reasoning patterns with our student interviews. However, our flux conceptual framework was largely based on student responses to our ion flux assessment items. Therefore, to further validate our learning progression framework, we needed a greater diversity of flux assessment items that investigated student thinking more broadly (i.e., about bulk flow, water movement) across physiological systems.

Practical Outcome (Epistemic Commitment 2). In designbased research, learning theories must "do real work" by 
TABLE 1. The preliminary flux learning progression framework characterizing the patterns of reasoning students may exhibit as they work toward mastery of flux reasoning. The student exemplars are from the ion flux formative assessment question presented in Figure 4 . The "I" divides a student's answers to the first and second parts of the question. Level 5 represents the most sophisticated ideas about flux phenomena.

\begin{tabular}{|c|c|c|}
\hline Level & Level descriptions & Student exemplars \\
\hline 5 & $\begin{array}{l}\text { Principle-based reasoning with full } \\
\text { consideration of interacting } \\
\text { components }\end{array}$ & $\begin{array}{l}\text { Change the membrane potential to }-100 \mathrm{mV} / \text { The negative charge in the cell will put a greater } \\
\text { driving force for the positively charged potassium than the concentration gradient forcing it } \\
\text { out. }\end{array}$ \\
\hline 4 & $\begin{array}{l}\text { Emergent principle-based reasoning } \\
\text { using individual components }\end{array}$ & $\begin{array}{l}\text { Decrease the concentration gradient or make the electrical gradient more positive/the concentra- } \\
\text { tion gradient and electrical gradient control the motion of charged particles. }\end{array}$ \\
\hline 3 & $\begin{array}{l}\text { Students use fragments of the } \\
\text { principle to reason }\end{array}$ & $\begin{array}{l}\text { Change concentration of outside } \mathrm{K} / \mathrm{If} \text { the concentration of } K \text { outside the cell is larger than the } \\
\text { concentration of } K \text { inside the cell, more } \mathrm{K} \text { will rush into the cell. }\end{array}$ \\
\hline 2 & $\begin{array}{l}\text { Students provide storytelling } \\
\text { explanations that are } \\
\text { nonmechanistic }\end{array}$ & $\begin{array}{l}\text { Close voltage-gated potassium channels/When the } V-K+\text { channels are closed then we will move } \\
\text { back toward a resting membrane potential meaning that } \mathrm{K}+\text { ions will move into the cell } \\
\text { causing the } \mathrm{mV} \text { to go from }-90 \mathrm{mV} \text { (K+ electrical potential) to }-70 \mathrm{mV} \text { (RMP). }\end{array}$ \\
\hline 1 & $\begin{array}{l}\text { Students provide nonmechanistic } \\
\text { (e.g., teleological) explanations }\end{array}$ & $\begin{array}{l}\text { Transport proteins/Needs help to cross membrane because it wouldn't do it readily since it's } \\
\text { charged. }\end{array}$ \\
\hline
\end{tabular}

improving student learning in real-world settings (DBR Collective, 2003). Therefore, design-based researchers must reflect on whether or not the data they collected show evidence that the instructional tools improved student learning (Cobb et al., 2003; Sharma and McShane, 2008). We determined whether our flux-based instructional approach aided student learning by analyzing the kinds of answers students provided to our assessment questions. Specifically, we considered students who reasoned at level 4 or above as demonstrating productive flux reasoning. Because almost half of students were reasoning at level 4 or 5 on the post-unit assessment after experiencing the instructional tools in the neurophysiology unit (in Spring 2017), we concluded that our tools supported student learning in physiology. Additionally, we noticed that students used language in their explanations that directly tied to the Flux Reasoning Tool (Figure 2), which instructed them to use arrows to indicate the magnitude and direction of gradient-driving forces. For example, in a posttest response to our ion flux item (Figure 4), one student wrote:

Ion movement is a function of concentration and electrical gradients. Which arrow is stronger determines the movement of $\mathrm{K}+$. We can make the electrical arrow bigger and pointing in by making the membrane potential more negative than Ek [i.e., potassium's equilibrium potential]. We can make the concentration arrow bigger and pointing in by making a very strong concentration gradient pointing in.

Given that almost half of students reasoned at level 4 or above, and that students used language from the Flux Reasoning Tool, we concluded that using fundamental concepts was a productive instructional approach for improving student learning in physiology and that our instructional tools aided student learning. However, some students in the 2016-2017 academic year continued to apply flux ideas more narrowly than intended (i.e., for ion and simple diffusion cases, but not water flux or bulk flow). This suggested that students had developed nascent flux conceptual frameworks after experiencing the instructional tools but could use more support to realize the broad applicability of this principle. Also, although our cross-sectional interview approach demonstrated how students' ideas, overall, could change after experiencing the instructional tools, it did not pro- vide information about how a student developed flux reasoning.

Reflecting on practical outcomes also means interpreting any learning gains in the context of the learning ecology. This reflection allowed us to identify whether there were particular aspects of the instructional tools that were better at supporting learning than others (DBR Collective, 2003). Indeed, this was critical for our understanding why $42 \%$ of students scored at level 3 and above on the pre-unit ion assessment in the Spring of 2017 , while only $2 \%$ of students scored level 3 and above in Autumn of 2016. When we reviewed notes of the Spring 2017 implementation scheme, we saw that the pretest was due at the end of the first day of class after students had been exposed to ion flux ideas in class and in a reading/video assignment about ion flow, which may be one reason for the students' high performance on the pretest. Consequently, we could not tell whether students' initial high performance was due to their learning from the activities in the first day of class or for other reasons we did not measure. It also indicated we needed to close pretests before the first day of class for a more accurate measure of students' incoming ideas and the effectiveness of the instructional tools employed at the beginning of the unit.

Design Principles (Epistemic Commitment 3). Although design-based research is enacted in local contexts (i.e., a particular classroom), its purpose is to inform learning ecologies that have broad applications to improve learning and teaching (Edelson, 2002; Cobb et al., 2003). Therefore, design-based research should produce design principles that describe characteristics of learning environments that researchers and instructors can use to develop instructional tools specific to their local contexts (e.g., Edelson, 2002; Subramaniam et al., 2015). Consequently, the design principles must balance specificity with adaptability so they can be used broadly to inform instruction (Collins et al., 2004; Barab, 2014).

From our first cycle of design-based research, we developed the following design principles: 1) Key scientific concepts should provide an overarching framework for course organization. This way, the individual components that make up a course, like instructional units, activities, practice problems, and assessments, all reinforce the centrality of the key concept. 2) Instructional tools should explicitly articulate the principle of 
interest, with specific guidance on how that principle is applied in context. This stresses the applied nature of the principle and that it is more than a fact to be memorized. 3) Instructional tools need to show specific instances of how the principle is applied in multiple contexts to combat students' narrow application of the principle to a limited number of contexts.

\section{Design-Based Research Cycle 2, Phase 1: Redesign and Refine the Experiment}

The last "epistemic commitment" Sandoval (2014) articulated was that design-based research be an iterative process with an eye toward continually refining the instructional tools, based on evidence of student learning, to produce more robust learning environments. By viewing educational inquiry as formative research, design-based researchers recognize the difficulty in accounting for all variables that could impact student learning, or the implementation of the instructional tools, a priori (Collins et al., 2004). Robust instructional designs are the products of trial and error, which are strengthened by a systematic analysis of how they perform in real-world settings.

To continue to advance our work investigating student thinking using the principle of flux, we began a second cycle of design-based research that continued to address the learning problem of helping students reason with fundamental scientific concepts. In this cycle, we largely focused on broadening the number of physiological systems that had accompanying formative assessment questions (i.e., beyond ion flux), collecting student reasoning from a more diverse population of students (e.g., upper division, allied heath, community college), and refining and validating the flux learning progression with both written and interview data in a student through time. We developed a suite of constructed-response flux assessment questions that spanned neuromuscular, cardiovascular, respiratory, renal, and plant physiological contexts and asked students about several kinds of flux: ion movement, diffusion, water movement, and bulk flow (29 total questions; available at beyondmultiplechoice.org). This would provide us with rich qualitative data that we could use to refine the learning progression. We decided to administer written assessments and conduct interviews in a pretest/posttest manner at the beginning and end of each unit both as a way to increase our data about student reasoning and to provide students with additional practice using flux reasoning across contexts.

From this second round of designing instructional tools (i.e., broader range of assessment items), testing them in the classroom (i.e., administering the assessment items to diverse student populations), evaluating the tools (i.e., developing learning progression-aligned rubrics across phenomena from student data, tracking changes in the frequency distribution of students across levels through time), and reflecting on the tools' success, we would develop a more thorough and robust characterization of how students use flux across systems that could better inform our creation of new instructional tools to support student learning.

\section{HOW CAN DESIGN-BASED RESEARCH EXTEND AND ENRICH BER?}

While design-based research has primarily been used in educational inquiry at the $\mathrm{K}-12$ level (see Reiser et al., 2001; Mohan et al., 2009; Jin and Anderson, 2012), other science disciplines at undergraduate institutions have begun to employ this methodology to create robust instructional approaches (e.g., Szteinberg et al., 2014 in chemistry; Hake, 2007, and Sharma and McShane, 2008, in physics; Kelly, 2014, in engineering). Our own work, as well as that by Zagallo et al. (2016), provides two examples of how designbased research could be implemented in BER. Below, we articulate some of the ways incorporating design-based research into BER could extend and enrich this field of educational inquiry.

\section{Design-Based Research Connects Theory with Practice}

One critique of BER is that it does not draw heavily enough on learning theories from other disciplines like cognitive psychology or the learning sciences to inform its research (Coley and Tanner, 2012; Dolan, 2015; Peffer and Renken, 2016; Davidesco and Milne, 2019). For example, there has been considerable work in BER developing concept inventories as formative assessment tools that identify concepts students often struggle to learn (e.g., Marbach-Ad et al., 2009; McFarland et al., 2017; Summers et al., 2018). However, much of this work is detached from a theoretical understanding of why students hold misconceptions in the first place, what the nature of their thinking is, and the learning mechanisms that would move students to a more productive understanding of domain ideas (Alonzo, 2011). Using design-based research to understand the basis of students' misconceptions would ground these practical learning problems in a theoretical understanding of the nature of student thinking (e.g., see Coley and Tanner, 2012, 2015; Gouvea and Simon, 2018) and the kinds of instructional tools that would best support the learning process.

\section{Design-Based Research Fosters Collaborations across Disciplines}

Recently, there have been multiple calls across science, technology, engineering, and mathematics education fields to increase collaborations between BER and other disciplines so as to increase the robustness of science education research at the collegiate level (Coley and Tanner, 2012; NRC, 2012; Talanquer, 2014; Dolan, 2015; Peffer and Renken, 2016; Mestre et al., 2018; Davidesco and Milne, 2019). Engaging in design-based research provides both a mechanism and a motivation for fostering interdisciplinary collaborations, as it requires the design team to have theoretical knowledge of how students learn, domain knowledge of practical learning problems, and instructional knowledge for how to implement instructional tools in the classroom (Edelson, 2002; Hoadley, 2004; Wang and Hannafin, 2005; Anderson and Shattuck, 2012). For example, in our current work, our research team consists of two discipline-based education learning scientists from an R1 institution, two physiology education researchers/instructors (one from an R1 institution the other from a community college), several physiology disciplinary experts/instructors, and a K-12 science education expert.

Design-based research collaborations have several distinct benefits for BER: first, learning or cognitive scientists could provide theoretical and methodological expertise that may be unfamiliar to biology education researchers with traditional science backgrounds (Lo et al., 2019). This would both improve the rigor of the research project and provide biology education 
researchers with the opportunity to explore ideas and methods from other disciplines. Second, collaborations between researchers and instructors could help increase the implementation of evidence-based teaching practices by instructors/faculty who are not education researchers and would benefit from support while shifting their instructional approaches (Eddy et al., 2015). This may be especially true for community college and primarily undergraduate institution faculty who often do not have access to the same kinds of resources that researchers and instructors at research-intensive institutions do (Schinske et al., 2017). Third, making instructors an integral part of a designbased research project ensures they are well versed in the theory and learning objectives underlying the instructional tools they are implementing in the classroom. This can improve the fidelity of implementation of the instructional tools, because the instructors understand the tools' theoretical and practical purposes, which has been cited as one reason there have been mixed results on the impact of active learning across biology classes (Andrews et al., 2011; Borrego et al., 2013; Lee et al., 2018; Offerdahl et al., 2018). It also gives instructors agency to make informed adjustments to the instructional tools during implementation that improve their practical applications while remaining true to the goals of the research (Hoadley, 2004).

\section{Design-Based Research Invites Using Mixed Methods to Analyze Data}

The diverse nature of the data that are often collected in designbased research can require both qualitative and quantitative methodologies to produce a rich picture of how the instructional tools and their implementation influenced student learning (Anderson and Shattuck, 2012). Using mixed methods may be less familiar to biology education researchers who were primarily trained in quantitative methods as biologists (Lo et al., 2019). However, according to Warfa (2016, p. 2), "Integration of research findings from quantitative and qualitative inquiries in the same study or across studies maximizes the affordances of each approach and can provide better understanding of biology teaching and learning than either approach alone." Although the number of BER studies using mixed methods has increased over the past decade (Lo et al., 2019), engaging in design-based research could further this trend through its collaborative nature of bringing social scientists together with biology education researchers to share research methodologies from different fields. By leveraging qualitative and quantitative methods, design-based researchers unpack "mechanism and process" by characterizing the nature of student thinking rather than "simply reporting that differences did or did not occur" (Barab, 2014, p. 158), which is important for continuing to advance our understanding of student learning in BER (Dolan, 2015; Lo et al., 2019).

\section{CHALLENGES TO IMPLEMENTING DESIGN-BASED RESEARCH IN BER}

As with any methodological approach, there can be challenges to implementing design-based research. Here, we highlight three that may be relevant to BER.

\section{Collaborations Can Be Difficult to Maintain}

While collaborations between researchers and instructors offer many affordances (as discussed earlier), the reality of connect- ing researchers across departments and institutions can be challenging. For example, Peffer and Renken (2016) noted that different traditions of scholarship can present barriers to collaboration where there is not mutual respect for the methods and ideas that are part and parcel to each discipline. Additionally, Schinske et al. (2017) identified several constraints that community college faculty face for engaging in BER, such as limited time or support (e.g., infrastructural, administrative, and peer support), which could also impact their ability to form the kinds of collaborations inherent in design-based research. Moreover, the iterative nature of design-based research requires these collaborations to persist for an extended period of time. Attending to these challenges is an important part of forming the design team and identifying the different roles researchers and instructors will play in the research.

\section{Design-Based Research Experiments Are Resource Intensive}

The focus of design-based research on studying learning ecologies to uncover mechanisms of learning requires that researchers collect multiple data streams through time, which often necessitates significant temporal and financial resources (Collins et al., 2004; O’Donnell, 2004). Consequently, researchers must weigh both practical as well as methodological considerations when formulating their experimental design. For example, investigating learning mechanisms requires that researchers collect data at a frequency that will capture changes in student thinking (Siegler, 2006). However, researchers may be constrained in the number of data-collection events they can anticipate depending on: the instructor's ability to facilitate in-class collection events or solicit student participation in extracurricular activities (e.g., interviews); the cost of technological devices to record student conversations; the time and logistical considerations needed to schedule and conduct student interviews; the financial resources available to compensate student participants; the financial and temporal costs associated with analyzing large amounts of data.

Identifying learning mechanisms also requires in-depth analyses of qualitative data as students experience various instructional tools (e.g., microgenetic methods; Flynn et al., 2006; Siegler, 2006). The high intensity of these in-depth analyses often limits the number of students who can be evaluated in this way, which must be balanced with the kinds of generalizations researchers wish to make about the effectiveness of the instructional tools (O'Donnell, 2004). Because of the large variety of data streams that could be collected in a design-based research experiment-and the resources required to collect and analyze them-it is critical that the research team identify a priori how specific data streams, and the methods of their analysis, will provide the evidence necessary to address the theoretical and practical objectives of the research (see the following section on experimental rigor; Sandoval, 2014). These are critical management decisions because of the need for a transparent, systematic analysis of the data that others can scrutinize to evaluate the validity of the claims being made (Cobb et al., 2003).

\section{Concerns with Experimental Rigor}

The nature of design-based research, with its use of narrative to characterize versus control experimental environments, has drawn concerns about the rigor of this methodological 
approach. Some have challenged its ability to produce evidence-based warrants to support its claims of learning that can be replicated and critiqued by others (Shavelson et al., 2003; Hoadley, 2004). This is a valid concern that design-based researchers, and indeed all education researchers, must address to ensure their research meets established standards for education research (NRC, 2002).

One way design-based researchers address this concern is by "specifying theoretically salient features of a learning environment design and mapping out how they are predicted to work together to produce desired outcomes" (Sandoval, 2014, p. 19). Through this process, researchers explicitly show before they begin the work how their theory of learning is embodied in the instructional tools to be tested, the specific data the tools will produce for analysis, and what outcomes will be taken as evidence for success. Moreover, by allowing instructional tools to be modified during the testing phase as needed, design-based researchers acknowledge that it is impossible to anticipate all aspects of the classroom environment that might impact the implementation of instructional tools, "as dozens (if not millions) of factors interact to produce the measureable outcomes related to learning" (Hoadley, 2004, p. 204; DBR Collective, 2003). Consequently, modifying instructional tools midstream to account for these unanticipated factors can ensure they retain their methodological alignment with the underlying theory and predicted learning outcomes so that inferences drawn from the design experiment accurately reflect what was being tested (Edelson, 2002; Hoadley, 2004). Indeed, Barab (2014) states, "the messiness of real-world practice must be recognized, understood, and integrated as part of the theoretical claims if the claims are to have real-world explanatory value" (p. 153).

\section{CONCLUSIONS}

In this essay, we have highlighted some of the ways designbased research can advance-and expand upon-research done in biology education. These ways include:

- providing a methodology that integrates theories of learning with practical experiences in classrooms,

- using a range of analytical approaches that allow for researchers to uncover the underlying mechanisms of student thinking and learning,

- fostering interdisciplinary collaborations among researchers and instructors, and

- characterizing learning ecologies that account for the complexity involved in student learning

By employing this methodology from the learning sciences, biology education researchers can enrich our current understanding of what is required to help biology students achieve their personal and professional aims during their college experience. It can also stimulate new ideas for biology education that can be discussed and debated in our research community as we continue to explore and refine how best to serve the students who pass through our classroom doors.

\section{ACKNOWLEDGMENTS}

We thank the UW Biology Education Research Group's (BERG) feedback on drafts of this essay as well as Dr. L. Jescovich for last-minute analyses. This work was supported by a National
Science Foundation award (NSF DUE 1661263/1660643). Any opinions, findings, and conclusions or recommendations expressed in this material are those of the author(s) and do not necessarily reflect the views of the NSF. All procedures were conducted in accordance with approval from the Institutional Review Board at the University of Washington (52146) and the New England Independent Review Board (120160152).

\section{REFERENCES}

Alonzo, A. C. (2011). Learning progressions that support formative assessment practices. Measurement, 9(2/3), 124-129.

Anderson, T., \& Shattuck, J. (2012). Design-based research: A decade of progress in education research? Educational Researcher, 41(1), $16-25$

Andrews, T. M., Leonard, M. J., Colgrove, C. A., \& Kalinowski, S. T. (2011) Active learning not associated with student learning in a random sample of college biology courses. CBE-Life Sciences Education, 10(4), 394-405.

Badenhorst, E., Hartman, N., \& Mamede, S. (2016). How biomedical misconceptions may arise and affect medical students' learning: A review of theoretical perspectives and empirical evidence. Health Professions Education, 2(1), 10-17

Barab, S. (2014). Design-based research: A methodological toolkit for engineering change. In The Cambridge handbook of the learning sciences (2nd ed., pp. 151-170). Cambridge University Press. https://doi.org/ 10.1017/CBO9781139519526.011

Barab, S., \& Squire, K. (2004). Design-based research: Putting a stake in the ground. Journal of the Learning Sciences, 13(1), 1-14.

Bell, P. (2004). On the theoretical breadth of design-based research in education. Educational Psychologist, 39(4), 243-253.

Borrego, M., Cutler, S., Prince, M., Henderson, C., \& Froyd, J. E. (2013). Fidelity of implementation of research-based instructional strategies (RBIS) in engineering science courses. Journal of Engineering Education, 102(3), $394-425$

Brown, A. L. (1992). Design experiments: Theoretical and methodological challenges in creating complex interventions in classroom settings Journal of the Learning Sciences, 2(2), 141-178.

Chi, M. T. H., Roscoe, R. D., Slotta, J. D., Roy, M., \& Chase, C. C. (2012). Misconceived causal explanations for emergent processes. Cognitive Science, 36(1), 1-61.

Cobb, P., Confrey, J., diSessa, A., Lehrer, R., \& Schauble, L. (2003). Design experiments in educational research. Educational Researcher, 32(1), 9-13.

Coley, J. D., \& Tanner, K. D. (2012). Common origins of diverse misconceptions: Cognitive principles and the development of biology thinking CBE-Life Sciences Education, 11(3), 209-215.

Coley, J. D., \& Tanner, K. (2015). Relations between intuitive biological thinking and biological misconceptions in biology majors and nonmajors. CBE-Life Sciences Education, 14(1). https://doi.org/10.1187/ cbe.14-06-0094

Collins, A., Joseph, D., \& Bielaczyc, K. (2004). Design research: Theoretical and methodological issues. Journal of the Learning Sciences, 13(1), 15-42.

Corcoran, T., Mosher, F. A., \& Rogat, A. D. (2009). Learning progressions in science: An evidence-based approach to reform (CPRE Research Report No. RR-63). Philadelphia, PA: Consortium for Policy Research in Education.

Davidesco, I., \& Milne, C. (2019). Implementing cognitive science and discipline-based education research in the undergraduate science classroom. CBE-Life Sciences Education, 18(3), es4.

Design-Based Research Collective. (2003). Design-based research: An emerging paradigm for educational inquiry. Educational Researcher, 32(1), 5-8.

Dolan, E. L. (2015). Biology education research 2.0. CBE-Life Sciences Education, 14(4), ed1.

Duschl, R., Maeng, S., \& Sezen, A. (2011). Learning progressions and teaching sequences: A review and analysis. Studies in Science Education, 47(2), 123-182. 
Eddy, S. L., Converse, M., \& Wenderoth, M. P. (2015). PORTAAL: A classroom observation tool assessing evidence-based teaching practices for active learning in large science, technology, engineering, and mathematics classes. CBE-Life Sciences Education, 14(2), ar23.

Edelson, D. C. (2002). Design research: What we learn when we engage in design. Journal of the Learning Sciences, 11(1), 105-121.

Flynn, E., Pine, K., \& Lewis, C. (2006). The microgenetic method-Time for change? The Psychologist, 19(3), 152-155.

Gouvea, J. S., \& Simon, M. R. (2018). Challenging cognitive construals: A dynamic alternative to stable misconceptions. CBE-Life Sciences Education, 17(2), ar34

Gunckel, K. L., Mohan, L., Covitt, B. A., \& Anderson, C. W. (2012). Addressing challenges in developing learning progressions for environmental science literacy. In Alonzo, A. C., \& Gotwals, A. W. (Eds.), Learning progressions in science: Current challenges and future directions (pp. 39-75). Rotterdam: SensePublishers. https://doi.org/10.1007/978-94-6091-824-7_4

Hake, R. R. (2007). Design-based research in physics education research: A review. In Kelly, A. E., Lesh, R. A., \& Baek, J. Y. (Eds.), Handbook of design research methods in mathematics, science, and technology education (p. 24). New York: Routledge.

Hoadley, C. M. (2004). Methodological alignment in design-based research. Educational Psychologist, 39(4), 203-212.

Jackson, M., Tran, A., Wenderoth, M. P., \& Doherty, J. H. (2018). Peer vs. self-grading of practice exams: Which is better? CBE-Life Sciences Education, 17(3), es44. https://doi.org/10.1187/cbe.18-04-0052

Jin, H., \& Anderson, C. W. (2012). A learning progression for energy in socio-ecological systems. Journal of Research in Science Teaching, 49(9), 1149-1180.

Joseph, D. (2004). The practice of design-based research: Uncovering the interplay between design, research, and the real-world context. Educational Psychologist, 39(4), 235-242.

Kelly, A. E. (2014). Design-based research in engineering education. In Cambridge handbook of engineering education research (pp. 497-518). New York, NY: Cambridge University Press. https://doi.org/10.1017/ CBO9781139013451.032

Lee, C. J., Toven-Lindsey, B., Shapiro, C., Soh, M., Mazrouee, S., Levis-Fitzgerald, M., \& Sanders, E. R. (2018). Error-discovery learning boosts student engagement and performance, while reducing student attrition in a bioinformatics course. CBE-Life Sciences Education, 17(3), ar40. https:// doi.org/10.1187/cbe.17-04-0061

Lo, S. M., Gardner, G. E., Reid, J., Napoleon-Fanis, V., Carroll, P., Smith, E., \& Sato, B. K. (2019). Prevailing questions and methodologies in biology education research: A longitudinal analysis of research in CBE-life sciences education and at the society for the advancement of biology education research. CBE-Life Sciences Education, 18(1), ar9.

Marbach-Ad, G., Briken, V., El-Sayed, N. M., Frauwirth, K., Fredericksen, B., Hutcheson, S., ... \& Smith, A. C. (2009). Assessing student understanding of host pathogen interactions using a concept inventory. Journal of Microbiology \& Biology Education, 10(1), 43-50.

McFarland, J. L., Price, R. M., Wenderoth, M. P., Martinková, P., Cliff, W., Michael, J., ... \& Wright, A. (2017). Development and validation of the homeostasis concept inventory. CBE-Life Sciences Education, 16(2), ar35.

McKenney, S., \& Reeves, T. C. (2013). Systematic review of design-based research progress: Is a little knowledge a dangerous thing? Educational Researcher, 42(2), 97-100.

Mestre, J. P., Cheville, A., \& Herman, G. L. (2018). Promoting DBER-cognitive psychology collaborations in STEM education. Journal of Engineering Education, 107(1), 5-10

Michael, J. A. (2007). What makes physiology hard for students to learn? Results of a faculty survey. AJP: Advances in Physiology Education, 31(1), 34-40.

Michael, J. A., Modell, H., McFarland, J., \& Cliff, W. (2009). The "core principles" of physiology: What should students understand? Advances in Physiology Education, 33(1), 10-16.

Middleton, J., Gorard, S., Taylor, C., \& Bannan-Ritland, B. (2008). The "compleat" design experiment: From soup to nuts. In Kelly, A. E., Lesh, R. A., \& Baek, J. Y. (Eds.), Handbook of design research methods in education: Innovations in science, technology, engineering, and mathematics learning and teaching (pp. 21-46). New York, NY: Routledge.
Modell, H. I. (2000). How to help students understand physiology? Emphasize general models. Advances in Physiology Education, 23(1), S101-S107.

Mohan, L., Chen, J., \& Anderson, C. W. (2009). Developing a multi-year learning progression for carbon cycling in socio-ecological systems. Journal of Research in Science Teaching, 46(6), 675-698.

National Academies of Sciences, Engineering, and Medicine. (2018). How People Learn II: Learners, Contexts, and Cultures. Washington, DC: National Academies Press. Retrieved June 24, 2019, from https://doi. org/10.17226/24783

National Research Council (NRC). (2002). Scientific research in education Washington, DC: National Academies Press. Retrieved January 31, 2019, from https://doi.org/10.17226/10236

NRC. (2007). Taking science to school: Learning and teaching science in grades K-8. Washington, DC: National Academies Press. Retrieved March 22, 2019, from www.nap.edu/catalog/11625/taking-science-to-school-learning -and-teaching-science-in-grades. https://doi.org/10.17226/11625

NRC. (2012). Discipline-based education research: Understanding and improving learning in undergraduate science and engineering. Washington, DC: National Academies Press. Retrieved from www.nap.edu/catalog/ 13362/discipline-based-education-research-understanding-and -improving-learning-in-undergraduate. https://doi.org/10.17226/13362

NRC. (2018). How people learn II: Learners, contexts, and cultures. Washington, DC: National Academies Press. Retrieved from www.nap.edu/ read/24783/chapter/7. https://doi.org/10.17226/24783

O'Donnell, A. M. (2004). A commentary on design research. Educational Psychologist, 39(4), 255-260.

Offerdahl, E. G., McConnell, M., \& Boyer, J. (2018). Can I have your recipe? Using a fidelity of implementation (FOI) framework to identify the key ingredients of formative assessment for learning. CBE-Life Sciences Education, 17(4), es16.

Peffer, M., \& Renken, M. (2016). Practical strategies for collaboration across discipline-based education research and the learning sciences. CBELife Sciences Education, 15(4), es11.

Reiser, B. J., Smith, B. K., Tabak, I., Steinmuller, F., Sandoval, W. A., \& Leone, A. J. (2001). BGulLE: Strategic and conceptual scaffolds for scientific inquiry in biology classrooms. In Carver, S. M., \& Klahr, D. (Eds.), Cognition and instruction: Twenty-five years of progress (pp. 263-305). Mahwah, $\mathrm{NJ}$ : Lawrence Erlbaum Associates, Inc.

Sandoval, W. (2014). Conjecture mapping: An approach to systematic educational design research. Journal of the Learning Sciences, 23(1), 18-36.

Sandoval, W. A., \& Bell, P. (2004). Design-based research methods for studying learning in context: Introduction. Educational Psychologist, 39(4), 199-201.

Schinske, J. N., Balke, V. L., Bangera, M. G., Bonney, K. M., Brownell, S. E., Carter, R. S., ... \& Corwin, L. A. (2017). Broadening participation in biology education research: Engaging community college students and faculty. CBE-Life Sciences Education, 16(2), mr1.

Scott, E., Anderson, C. W., Mashood, K. K., Matz, R. L., Underwood, S. M., \& Sawtelle, V. (2018). Developing an analytical framework to characterize student reasoning about complex processes. CBE-Life Sciences Education, 17(3), ar49. https://doi.org/10.1187/cbe.17-10-0225

Scott, E., Wenderoth, M. P., \& Doherty, J. H. (2019). Learning progressions: An empirically grounded, learner-centered framework to guide biology instruction. CBE-Life Sciences Education, 18(4), es5. https://doi .org/10.1187/cbe.19-03-0059

Sharma, M. D., \& McShane, K. (2008). A methodological framework for understanding and describing discipline-based scholarship of teaching in higher education through design-based research. Higher Education Research \& Development, 27(3), 257-270.

Shavelson, R. J., Phillips, D. C., Towne, L., \& Feuer, M. J. (2003). On the science of education design studies. Educational Researcher, 32(1), 25-28.

Siegler, R. S. (2006). Microgenetic analyses of learning. In Damon, W., \& Lerner, R. M. (Eds.), Handbook of child psychology (pp. 464-510). Hoboken, NJ: John Wiley \& Sons, Inc. https://doi.org/10.1002/ 9780470147658.chpsy0211

Stringer, E. T. (2013). Action research. Thousand Oaks, CA: Sage Publications, Inc.

Subramaniam, M., Jean, B. S., Taylor, N. G., Kodama, C., Follman, R., \& Casciotti, D. (2015). Bit by bit: Using design-based research to improve the health literacy of adolescents. JMIR Research Protocols, 4(2), e62. 


\section{E. E. Scott et al.}

Summers, M. M., Couch, B. A., Knight, J. K., Brownell, S. E., Crowe, A. J., Semsar, K., ... \& Batzli, J. (2018). EcoEvo-MAPS: An ecology and evolution assessment for introductory through advanced undergraduates. CBELife Sciences Education, 17(2), ar18.

Szteinberg, G., Balicki, S., Banks, G., Clinchot, M., Cullipher, S., Huie, R., ... \& Sevian, H. (2014). Collaborative professional development in chemistry education research: Bridging the gap between research and practice. Journal of Chemical Education, 91(9), 1401-1408.

Talanquer, V. (2014). DBER and STEM education reform: Are we up to the challenge? Journal of Research in Science Teaching, 51(6), 809-819.

Wang, F., \& Hannafin, M. J. (2005). Design-based research and technologyenhanced learning environments. Educational Technology Research and Development, 53(4), 5-23.
Wang, J.-R. (2004). Development and validation of a Two-tier instrument to examine understanding of internal transport in plants and the human circulatory system. International Journal of Science and Mathematics Education, 2(2), 131-157.

Warfa, A.-R. M. (2016). Mixed-methods design in biology education research: Approach and uses. CBE-Life Sciences Education, 15(4), rm5.

Windschitl, M., Thompson, J., Braaten, M., \& Stroupe, D. (2012). Proposing a core set of instructional practices and tools for teachers of science. Science Education, 96(5), 878-903.

Zagallo, P., Meddleton, S., \& Bolger, M. S. (2016). Teaching real data interpretation with models (TRIM): Analysis of student dialogue in a large-enrollment cell and developmental biology course. CBE-Life Sciences Education, 15(2), ar17. 